\title{
Limites do mando, limites do mundo: a relação entre identidades de gênero e identidades espaciais no nordeste do começo do século
}

\author{
Durval Muniz de ALBUQUERQUE JÚNIOR*
}

\begin{abstract}
RESUMO
Este texto examina a relação entre as mudanças históricas na sociedade tradicional do engenho, no nordeste brasileiro, no começo do século XX, e a alteração nas percepções espaciais que se expressam em uma série de metáforas que emergem tanto no discurso memorialístico, como no discurso literário produzido por homens ligados a esta elite em declínio social e econômico. Estes textos falam do encurtamento do mundo, de sufocamentos, de limites cada vez mais rigorosos para a vida dos homens. Parece haver uma relação entre mudanças espaciais e mudanças nos códigos sociais e de gênero, à medida que o mesmo mundo que parece vir se encurtando para os homens, parece vir se alargando para as mulheres. Os homens se sentem cada vez mais presos e falam que as mulheres estão cava vez mais à solta. Os espaços que emergem com a sociedade urbana e industrial, espaços disciplinares, ao mesmo tempo em que aparecem nestes discursos como limitadores da vida dos homens, surgem como espaços de libertação das mulheres e de inversão perigosa das relações tradicionais de gênero. Numa sociedade que estaria se feminilizando, os homens estariam cada vez mais sem espaço.
\end{abstract}

Palavras-chave: percepções espaciais, mudanças históricas, discursos masculinos, nordeste brasileiro, início do século XX.

\begin{abstract}
This paper concerns the historical and social changes the tradicional sugar mil society faced in the northeast of Brazil in the early 20th century, and the changes in the space perceptions expressed through a number of metaphors which occur both in memoirs or literary discourses

* Professor Adjunto do Departamento de História e Geografia da Universidade Federal da
\end{abstract} Paraíba - Campus II - Campina Grande. 
used by the male group from the decadent elite. Those discourses speak about the curbing of the world to men, the suffocation feeling caused by stricter limits and places arising from an urban industrial society symbolized by the mills. These texts also refer to the shortening of male spaces related to a dangerous widening of female spaces. The same institutional and disciplinary spaces that mean imprisonment for men mean freedom to womem. These male discourses combine what is call ed a feminization society and consequent broadening of female boundaries and the reduction of spaces for the men who then face the limitions in their command and in their world.

Key-words: northeast, in the early 20th century, space perceptions, historic changes, gender relations.

Quando lemos as memórias ou os romances escritos pelos homens que viveram a transição da sociedade escravista para a sociedade burguesa, no começo do século, no norte/nordeste do país, nos chama a atenção a profusão de metáforas espaciais que são utilizadas para falar destas mudanças. Os textos falam da ruína de uma determinada percepção espacial, da ruína de uma geografia marcada pela relação afetiva entre homem e terra, homem e bichos; relação esta em que os homens estariam muito mais próximos da natureza, viveriam de forma harmônica com o espaço que os cercava. Estes discursos podem ser considerados, inclusive, pioneiros na denúncia da destruição da natureza regional, vista como produto do afastamento do homem e da terra, como fruto da invasão do espaço agrário tradicional por forças estranhas a este ambiente, sejam forças econômicas, sejam forças políticas. A sensação de que o próprio espaço se tornava cada vez mais estranho, que o mundo escapava de seus próprios pés, é uma constante no discurso destes homens saídos de uma elite em franco processo de declínio social. O senhor de engenho ou o coronel tradicional do sertão parecem perceber que o espaço antes visto como natural, estático e imutável, se move contra eles. Forças tectônicas que, às vezes parecem não compreenderem bem, fazem seus territórios tradicionais desabarem, tornandoos homens cada vez mais sem lugar no mundo e na sociedade, ou seja, seres desterritorializados. Veja o que diz Gilberto Freyre no prefácio às memórias de Júlio Bello:

A usina separou o grande proprietário não só do operariado que era uma segunda família do senhor - como da paisagem e 
dos rios, outrora tão ligados à vida dos homens e hoje uns mictórios por onde as fábricas descarregam a calda fedorenta... Daí uma nova forma de relações entre o patrão e o operário; entre o homem e a terra. A distância social e psíquica entre eles tornou-se maior. Tornou-se imensa.

Desapareceu quase todo o lirismo nas relações do homem com a paisagem, com a mata, com o animal, com o rio, com a planta, com a terra, com os outros homens. ${ }^{1}$

Estes textos falam da transição de um espaço agrário produzido e percebido através de relações marcadas pela pessoalidade, pelo paternalismo e, principalmente, pelo poder autoritário e discricionário de um chefe para um espaço agrário atravessado cada vez mais pelo anonimato do capital e do empresariado moderno. Eles falam de uma despersonalização da própria terra; já não se sabe a quem pertence cada engenho, cada fazenda; cada vez mais eles pertencem a uma entidade chamada usina, que não tem rosto, que não tem sangue, não tem tradição, não tem necessariamente vínculos familiares ou de vizinhança. Os nomes dos engenhos e das fazendas que estavam associados com as famílias e com seu passado, que as identificavam, agora pareciam perder a identidade. Passávamos de um espaço estriado pelas marcas pessoais, hereditárias, de família, para um espaço liso, anônimo, tedioso, que perdia suas marcas e marcos tradicionais, um espaço sem memória, em que os grandes mares sem fim de cana engoliam e destruíam todos os símbolos de um passado de glória e de poder de uma elite que se empobrecia, que perdia tudo, que via suas casas-grandes serem derrubadas, seus engenhos substituídos pela fábrica da usina. O espaço onde antes uma gameleira, uma mangueira, um rio, possuíam significados afetivos e pessoais e eram testemunhos de vidas e delas falavam, agora era o espaço sem afeto, sem lirismo do capitalista, ávido apenas por dinheiro:

Hoje, quem vai pelo magnífico traçado da estrada de rodagem... rodando a cinquienta quilômetros, para ora num, ora noutro ponto, junto das velhas casas-grandes em ruína, dos paredões das vetustas capelas, das taperas de antigos bangüês, para e Fundarpe, 1985. p. Xv.

1 FREYRE, G. Prefácio. In: BELLO, J. Memórias de um senhor de engenho. 3. ed. Recife: 
pergunta: "De quem é hoje este engenho?"A resposta é invariável: "Da Usina".

A Usina, a grande anônima, - é para todos a firma comercial do Recife. Eu, na meia fantasia com que muita vez encaro, graças a Deus, as coisas da vida, dou corpo e forma a essa tarrasca como se ela fosse uma espécie de Imperatriz Catarina, conquistadora insaciável de terras e deportadora terrível dos mujiks coronéis, senhores de engenho. Considero-a na minha fantasia como uma pessoa viva, com movimento próprio na trama social. Usina não é para mim como é para todos a firma A ou a firma B. A Usina que conquistou as terras e disseminou e deportou os seus velhos donos, é uma só. Não é uma pessoa ou grupo de pessoas que uma conjuntiva comercial une. É um sentimento. É o monopólio, o açambarcamento das terras, quase sem tolerância de uma distribuição mesmo pouco eqüitativa dos lucros da agricultura pela antiga classe dos cultivadores seculares da gleba. É quase o espírito de avareza. ${ }^{2}$

Nem que seja na fantasia, o antigo senhor de engenho, Júlio Bello, precisa personificar a usina e encará-la como fruto do sentimento de avareza. Seu anonimato é o que mais incomoda. É preciso lutar contra um inimigo que nunca se apresenta diretamente, que só manda emissários, que invade os territórios antes inexpugnáveis dos senhores. Tanto Harvey como Jameson $^{3}$ vão chamar a atenção para o fato de que um dos elementos definidores da modernidade é, exatamente, a mudança das relações com o espaço, a compressão espacial, à medida que o desenvolvimento tecnológico, dos meios de transporte e comunicação, além da mecanização da produção parecem produzir um encolhimento das distâncias e a alteração das percepções espaciais. Estes discursos lidam com uma série de imagens espaciais que parecem remeter a esse processo de alteração das escalas espaciais e de seus limites e fronteiras com a chegada do mundo moderno, urbano e industrial.

A dicotomia entre o largo e o curto atravessa, por exemplo, toda visão da passagem da antiga sociedade do engenho para a nova sociedade

2 BELLO, op. cit., p. 58-59.

3 Ver HARVEY, D. A condição pós-moderna. São Paulo: Loyola, 1993; JAMESON, F. Pós-modernismo: a lógica cultural do capitalismo tardio. São Paulo: Ática, 1996. 
urbana e da usina, nas memórias de Júlio Bello. Os antigos senhores de engenho tinham uma largueza de estar no mundo, que os faziam ficar anchos e esparramados na sociedade tradicional: eram quase sempre amplos no próprio corpo, gordos, espalhados pelas terras, pela casa, pelas varandas. Eram também largos de espírito, largos de caráter, atendendo a todos com generosidade, distribuindo de forma até imprevidente o que ganhavam com os parentes, aderentes e as pessoas pobres que a eles recorriam. Tudo neles parecia representar o excesso, fruto de um poder também sem limites. A geografia de seu mando e de seu mundo era, portanto, bastante ampla e sem limites definidos:

Residia no tempo do meu pai tanta gente no engenho e a terra dava tanto e tão bem para todos, que tenho por vezes a impressão, atualmente, em que já não é assim, que as terras minguaram.

Generoso até quase o desperdício pagava com usura os favores que recebia. Deixava mesmo que o explorassem com aquela excessiva liberalidade que era o apanágio da maioria dos homens bem nascidos das lavouras antigas: à graça do mais insignificante mimo que lhe dava um pobre, replicava a patacões de prata. Nem a largueza de ânimo, a grandiosidade, aquele espírito cavalheiresco e teatral de Sebastião Wanderley Chaves, do Rosário, subsistiam.

As figuras mais nobres da lavoura antiga extinguiram-se todas. Seus descendentes se vão também apagando em triste e imerecida pobreza. Os engenhos pertencem a pessoas que os não amam como os velhos senhores. As próprias terras parecem protestar contra o absenteísmo de seus naturais proprietários e, avaras, se encolhem e se recusam aos novos donos como mulher honesta a conquistadores. ${ }^{4}$

Estas memórias nos falam, na verdade, da redução do poder destas elites tradicionais. O domínio que antes era exercido, começando pelo espaço da casa, do engenho, e que se estendia por toda a sociedade circundante, começa a ser reduzido. São frequientes as queixas da invasão 
que os, antes inexpugnáveis, reinos dos senhores de terras começam a sofrer. Invasão dos agentes do Estado em processo de fortalecimento e dos agentes do capital, nacional ou internacional, que começam a intervir diretamente na produção e não apenas na circulação, como antigamente, o que Júlio Bello chama de industrialização da terra. A progressiva separação entre espaço público e espaço privado, que começa a se esboçar com o progressivo fortalecimento do Estado, que já conta com novos grupos urbanos emergentes nos quais pode se apoiar, reflete-se na percepção espacial destas elites. $\mathrm{O}$ seu mundo, antes de limites amplos e indefinidos e ao mesmo tempo um mundo fechado e inexpugnável, que só podia ser penetrado com a permissão do dono, é progressivamente reduzido, encurtado, invadido, levando a que esta elite sinta uma sensação de sufocamento e de estrangulamento. Chegando a perda total das terras e dos espaços antes sob domínio, a maioria dos elementos das novas gerações antes ligadas a terra e que tinham nela os horizontes de sua própria vida, têm que procurar novos lugares, construir novos territórios existenciais, fora de seu mundo tradicional: têm que deixar a fazenda ou o engenho e migrarem para a cidade ou para o sul, ou mesmo, viverem de favor em terras alheias:

Olhava eu o meu avô como se ele fosse o engenho. A grandeza da terra era a sua grandeza. Fixara-se em mim a certeza de que o mundo inteiro estava ali dentro. Não podia haver nada que não fosse do meu avô. Lá ia o gado para o pastoreador, e era dele; lá saíam os carros-de-boi a gemer pela estrada ao peso das sacas de lã e dos sacos de açúcar, e tudo era dele; lá estavam as negras da cozinha, os moleques da estrebaria, os trabalhadores do eito, e tudo era dele. O sol nascia, as águas do céu se derramavam na terra, o rio corria, e tudo era dele...A minha impressão firme era que nada havia além dos limites do Corredor. Chegavam de longe portadores de outros engenhos. Ouvia apitar o trem na linha de ferro. Apesar de tudo, só havia de concreto mesmo o Engenho Corredor. ${ }^{5}$

5 RÊGO, J. L. do. Meus verdes anos. Rio de Janeiro: José Olympio, 1956. 
Estes discursos vão desenhando uma topografia afetiva dos espaços do passado e produzindo a idéia de um corte entre estas espacialidades poéticas, antes personalizadas com o espaço anônimo, seja da nova sociedade rural, seja da sociedade urbana. São espaços sob os quais eles não têm mais domínio, estes lhes fogem. Exprimem a diminuição da autoridade destes senhores, de sua capacidade de mandar, o que limita também o seu próprio mundo. O que parecem sentir de forma mais dolorosa é terem que dividir o poder com forças sociais emergentes, como os comerciantes, os industriais e mesmo os operários e trabalhadores rurais e urbanos:

Quando eu sucedi meu pai na sua casa-grande, já não gozavam os senhores de engenho desta zona de prerrogativas consideráveis de grandeza, poderio e respeito. Não era aquilo mais a miniatura de um reinado, e sim já a miniatura de um passado. O nível moral dos senhores rurais se elevara, seus costumes haviam se modificado, eles não se compraziam mais naquelas demasias, despropósitos e indecências a que Gilberto Freyre alude em Casa Grande e Senzala.

Em verdade, já naquele tempo a difusão das maneiras mais urbanas continha-os nos despropósitos e despotismos de tempos anteriores.

Nos primeiros quartéis do século passado eles foram, com efeito, homens todo poderosos: polícia e justiça dentro de suas terras eram eles. A terra conferia foros de nobreza: o nome patronímico desaparecia depois do de batismo para ser substituído pelo nome da propriedade.

Certos senhores arrogantes não perdoavam a mais razoável visita da polícia às suas propriedades. Reputavam-na um ultraje, de que cuidavam de desafrontar-se, fosse como fosse. Ainda hoje subsiste este prejuízo e em verdade as visitas da polícia aos engenhos valem, às vezes, por verdadeiros assaltos e trazem quase sempre inconvenientes.

Diante da casa-grande as cabeças se descobriam como diante de um templo, os lábios que falavam emudeciam, ou passavam a murmurar apenas as palavras da conversa em seu seguimento enquanto os interlocutores defrontavam-na, depois iam os lábios articulando mais alto, gradativamente, a conversa, a razão da distância que se ia pondo entre os que passavam e falavam e a residência do senhor de engenho. Se o Senhor chegava a uma porteira e se encontrava alguém que vinha em sentido inverso, quem vinha descobria-se diante de quem 
chegava, abrindo bem a porteira para que por ela pudesse passar, com franqueza, o senhor de engenho e toda a sua importância. E não a batia como ordinariamente se faz: ia com ela vagarosamente até o mourão, encostando-a com doçura. O Senhor de engenho passava: bater-lhe a porteira com força nas costas, era falta de respeito. No silêncio da noite, nem um chicote estralejava tangendo um comboio de animais por defronte da casa-grande: o HOMEM dormia. ${ }^{6}$

Ao se referirem ao encurtamento das distâncias e do mundo, estes discursos estão falando do encurtamento das distâncias sociais de fortuna e de poder entre as novas gerações da elite branca e a aproximação destes da condição social de negros e mestiços ou mesmo de brancos pobres, para os quais a nova sociedade oferecia possibilidades de ascensão social, embora, limitadas. O medo da inversão das hierarquias sociais e de cor é que está na base desta sensação de encurtamento do mundo. Espaços antes reservados somente para os membros das elites agora podiam ser ocupados por pessoas sem berço, sem tradição, sem sangue aristocrático. Os antigos senhores se viam limitados, inclusive, pela imposição de novos códigos de valores e costumes. Já não podiam agir discricionariamente como antes. Novos e rígidos códigos morais progressivamente implantados pela sociedade moderna e urbana limitavam as antigas expansões de violência e autoritarismo nas relações sociais.

O que podemos enxergar nas mudanças sociais em curso é uma profunda crise nos códigos que regiam a masculinidade. Esta é uma sociedade de homens em crise, homens que ao terem seu mando reduzido, sendo limitados por outros códigos de sociabilidade, já não podem reproduzir os antigos modelos de masculinidade e se sentem como homens moles, covardes, efeminados. A profunda nostalgia em relação a geração de seus avôs, mostram como estes homens não estão satisfeitos com a sua nova condição. A própria ocorrência do fato de que, cada vez mais, mulheres têm que assumir a direção do negócio das famílias, por terem se casado com maridos urbanizados e pouco preparados e afeitos aos negócios da fazenda ou do engenho, mostra esta crise da masculinidade tradicional:

6 BELLO, op. cit., p. 179-180. 
O engenho antigo era, por via de regra, uma escola de prepotência, de fanfarronice, de impostura, de mando sem discussão e de excessiva altivez. O que era virtude muita vez no engenho não convinha de modo nenhum ao funcionário público e ao comerciante. Carece-se de certa disciplina, tolerância e obediência, coisas que não se aprendiam na vida das casasgrandes.

Mesmo na geração posterior a minha, entre os meus, surgem de vez em quando exemplos de homens assim moles e resignados que se contentam com quase nada na vida ou esperam que lhes venham o pão de cada dia, sem o buscarem pelo trabalho, da generosidade de um parente: criaturas desfibradas e como aqueles velhos tios, quando muito plantadores de couves e criadores de galinha...As antigas famílias rurais de Pernambuco apresentam iguais exemplares de indolência que se vão fundindo tristemente, sem reação, no proletariado e na miséria geral. Contentam-se com o vago poder espiritual, quase tão sutil como um litúrgico perfume de incenso, de poderem continuar figurando nas festas do orago da capela como juiz da festa. Aquela derradeira sombra de poder lhe basta. $^{7}$

É constante também, nestas memórias, a percepção de que as mulheres começavam a ocupar lugares que antes não eram a elas destinados. Este processo de virilização das mulheres é acompanhado da sensação de enfraquecimento dos homens, que não são capazes mais de atualizarem os antigos modelos de comportamento masculino, contribuindo para a ruína das famílias e das propriedades. É como se os homens levados a freqüentar os melhores colégios e faculdades, ao se bacharelarem e se urbanizarem, perdessem a antiga fibra, se amiudassem na hora que eram chamados a assumir o lugar de seus antepassados. A própria perspectiva de vida para estas pessoas parecia se encurtar com este corte que vinha se estabelecendo entre o passado e o presente. Ao se amiudar o passado, se amiudavam com ele os próprios personagens masculinos que haviam sido, neste tempo, as figuras centrais na história do país e da região. Quando as mulheres começavam a fazer história, algo parecia estar errado:

7 BELLO, op. cit., p. 3, 5 e 6. 
O cinema transformou radicalmente os costumes da sociedade. Parece mesmo que esta transformação de costumes foi universal.

A mulher fuma, a mulher vota, a mulher é elegível, a mulher militariza-se, invadindo assim as grosseiras atribuições masculinas: perde com isto aquele misterioso encanto que o recato antigo lhe assegurava. ${ }^{8}$

A redução do poder social desta elite de homens brancos ou mestiços, vindos dos tempos de glória do Império, parece vir acompanhada da perda de poder também em suas relações com as mulheres. A urbanização dos costumes, a progressiva influência de uma nova sociabilidade parece levar ao encurtamento dos espaços dos homens, ao mesmo tempo em que as fronteiras do mundo se alargam para as mulheres. Fica claro, portanto, que as espacialidades, ou as formas de se perceber e significar os espaços, estão relacionadas com as relações sociais em que está inserido quem os observa e os qualifica. O espaço masculino do engenho tradicional, onde seu poder era incontestado, dá lugar ao espaço urbano e comercial onde homens que aprenderam apenas a mandar discricionariamente se tornam inadaptados. Vindos de uma sociedade escravista, em que não precisavam trabalhar, em que o que definia a masculinidade e um homem superior era a sua capacidade de infundir respeito, obediência e a autoridade, mesmo que fosse através do medo e da violência pessoal, os homens se tornam incapazes para atuar numa sociedade onde o que define a masculinidade e sua qualidade superior é sua capacidade de trabalho e de poder ser o provedor de seu lar.

As próprias metáforas que definiam a relação do masculino e do feminino com os espaços começam a ser alteradas. Os homens que antes viviam soltos, fora de casa, podendo se aventurar por diferentes lugares, se vêem cada vez mais presos a uma rotina estafante de trabalho. O homem de escritório, o funcionário público, o vendedor, o operário de fábrica já não têm as rédeas soltas como os antigos senhores, são cada vez mais encabrestados a uma vida rotineira, modorrenta, marcada por atividades repetitivas e cotidianas humilhações. A mulher que antes estava presa ao lar, à vida doméstica, quando não à camarinha e à cozinha, dependendo de

8 BELLO, op. cit., p. 18, 92. 
sua condição social, ia tomando as rédeas de suas vidas nas mãos, já respiravam novos ares, já saíam à rua para o estudo ou para o trabalho, mesmo que fosse nos mesmos lugares que para os homens pareciam ser prisões, mas que para elas eram indícios de liberdade.

Isto deixa claro que as percepções espaciais em uma sociedade têm que ser contextualizadas historicamente e podem variar dependendo do lugar social do sujeito que se relaciona com estes espaços. O mesmo espaço que para um homem podia significar a prisão, o encurtamento do mando e do mundo, podia significar para as mulheres a ampliação de seus horizontes, a liberdade de ir e vir, a sensação de que agora tinha um espaço só seu, onde podia mandar em sua própria vida. Os espaços são, pois, inclusive generizados, guardam significados distintos para homens e para mulheres em dados contextos históricos. O encurtamento dos espaços masculinos pode significar a ampliação dos espaços femininos. O mesmo espaço pode ser visto como prisão ou como liberdade dependendo do ponto de vista de quem observa. A fábrica que prendia os homens, soltava as mulheres, a cidade que limitava as aventuras masculinas, ampliava os horizontes das vidas das mulheres. O colégio que era a tortura de um menino de engenho, podia ser o deleite da sinhazinha, longe por algumas horas do olhar prescrutador do pai, da família:

O colégio, para mim, tornava-se mais ainda uma prisão, uma cadeia, com Pedro Muniz e Maria Luísa lá fora. Lembrava-me de um preso do Pilar, morador do engenho, que matara a José Gonçalo. A mulher amigara-se com outro, e ele na grade mandando recadinhos para ela. (...) E o pobre na cadeia sofrendo. Não sei por que minha memória ligava estes fatos ao meu amor por Maria Luísa. É que eu estava preso como o negro, não podia fazer o que Pedro Muniz estava fazendo para agradar à namorada. Ficava na grade com a angústia do morador do Santa Rosa. Ele olhava pelos buracos da prisão o povo debaixo do tamarindeiro, na feira de sábado. ${ }^{9}$

9 RÊGO, J. L. do. Doidinho. 16. ed. Rio de Janeiro: José Olympio, 1977. p. 85-86. Ver também, GALVÃO, A. de O. Amansando meninos. João Pessoa: UFPB, 1998. 
As instituições da sociedade disciplinar que emergiam: a escola, a fábrica, os órgãos públicos vão modificar profundamente a vida dos meninos de engenho, agora educados nas cidades e sendo subjetivamente produzidos por estes novos lócus institucionais. A "frouxidão" da vida nos engenhos bangüês, que idilicamente de tanto falam estes discursos, estava com os dias contados. Surgia um mundo onde a dominação masculina para ser reposta iria exigir dos homens uma alteração profunda em seus perfis, em seus comportamentos, em suas subjetividades. Iriam aprender dolorosamente que agora para poderem dominar, tinham que cada vez mais dominarem a si próprios. Antes de serem déspotas com os outros teriam que exercer um despotismo crescente sobre seus próprios desejos, sobre seus próprios costumes, sobre seus próprios corpos. Para preservar o mando, era preciso limitar o seu próprio mundo, de uma forma cada vez mais rigorosa. Homens como passarinhos presos nos próprios alçapões.

No entanto, a imagem que estes textos produzem são de homens incapazes de absorver a nova ética do trabalho, homens viciados pela escravidão a nada fazerem, homens amolecidos e desfibrados, que vão perdendo tudo o que possuem, tendo literalmente o seu mundo e o seu mando progressivamente reduzidos, sem conseguirem entender que vivem em um novo mundo, que exige novos valores e costumes. A largueza e a generosidade devem agora ser substituídos pelo espírito de previdência e poupança: o desperdício não se adequa a uma sociedade presidida pela acumulação. A própria assistência a um grande número de pessoas, principalmente de familiares, já não se coaduna com uma sociedade onde todo tipo de liberalidade pode significar prejuízo e falência. A própria família, antes extensa e vivendo em um consórcio no qual era possível o apoio dos parentes nas horas de dificuldades, já não parece mais ser uma realidade palpável, uma vez que cada grupo familiar começava a se fechar em seu egoísmo burguês.

Os antigos patriarcas de engenho e de fazenda, que estavam em crise por terem perdido suas antigas referências, parecem desorientados. Olham em volta e não conseguem enxergar mais o seu mundo: sentem-se estranhos e inatuais. Daí a necessidade de reviver estas territorialidades perdidas, nem que seja em forma de romance ou de memória. A necessidade que sentem de escrever e registrar este mundo que estava desabando nasce da própria percepção que a escritura era a única forma ainda disponível para dar materialidade a esta geografia em ruína. Literatura nascida da tristeza, do 
lamento, da nostalgia, da melancolia, diante de um mundo cujas fronteiras vinha se apagando.

Esses escritores das elites defendem a idéia de que a tristeza com o fim deste mundo não era só deles: o povo também teria ficado mais triste, pois já não festejavam como antes, já não tinham a proteção certa do senhor e os cuidados de assistência moral dada pela sinhazinha. A ilusão do salário os havia retirado aquilo que eles tinham acesso antes como: um pedaço de terra para plantar, um litro de leite ao final do dia, o acesso à caça e à pesca, uma parelha de roupa nas festas de fim de ano:

O homem da cidade comprou a usina e comprou as terras. Com esse utilitarismo comercial e as suas minúcias de deve e haver", de "lucros e perdas", com este espírito de detalhe do homem de negócio que investiga inteligentemente tudo e tudo anota e aproveita, e para aumentar a zona de culturas, invadiu com a lavoura de cana todos os recantos dos engenhos. Valendo-se, para sua defesa, de uma ilusória vantagem no salário, tomou, por via de regra, os pequenos sítios de mandioca e das outras lavouras secundárias do pobre. Este deixou de cultivar o trato da terra, que ordinariamente, a complacência e o espírito de equidade do Senhor de engenho antigo lhe outorgavam. Deixou os engenhos e passou a residir de preferência nos povoados e cidades do interior, vivendo exclusivamente do salário ilusoriamente melhorado.

Não tendo um palmo de terra que cultive, acaba por conformarse com essa resignação herdada de 300 anos de opressão, com o rigor dos ricos-homens e não o busca mais longe. Não reserva assim nada para os maus dias, perde mesmo a noção de necessidade de fazer alguma coisa para si só, de tudo que faz para os outros, alugando os braços. ${ }^{10}$

Não eram apenas, portanto, os espaços para os homens das elites que estavam se reduzindo, segundo estes discursos. Os homens pobres também estavam perdendo o acesso à terra, ainda precária que tenha sido a possibilidade de acesso dada anteriormente pela "generosidade" do

10 BELLO, op. cit., p. 133. 
senhor de engenho. Com as usinas estes são atirados para o espaço diminuto das pontas de ruas, onde eram convocados para trabalharem apenas nas tarefas ligadas à produção açucareira. Para estes homens do eito o mundo também estaria se encurtando, enquanto se alargava para o capitalista.

Este discurso memorialístico e literário nos permite mapear, portanto, as mudanças subjetivas trazidas pelo predomínio das novas relações mercantis e urbanas e a própria inadequação de uma série de sujeitos não preparados para vivenciarem este novo mundo. Fruto de uma mutação subjetiva, o mundo que estes escritores e memorialistas vivem após os anos trinta deste século, vitimou um determinado padrão de sociabilidade e produziu a ruína de muitas vidas, de muitas fortunas e a rearrumação do próprio espaço econômico e de poder em nível regional, seja poder público, seja poder privado. Há uma total rearrumação nos territórios sociais, com a mudança de hierarquias, com a complexificação da própria sociedade, multiplicando lugares de sujeito e as possibilidades de construção de territórios. Aquele mundo que parecia único, simples, unificado, um reino inexpugnável dos antigos potentados rurais, se fragmenta, se descobre vulnerável e sujeito ao caráter corrosivo do tempo e da história. As fronteiras do mundo que antes pareciam definitivamente estabelecidas, quando tudo parecia estar em seu lugar, sofrem rachaduras e deslocamentos incontornáveis: o chão foge, o mundo se torna escorregadio, um passo em falso pode significar a queda social, moral e política. Contra este mundo das incertezas e dos limites fluidos, das fronteiras em movimento, só mesmo a materialidade e a perenidade das margens do texto escrito para garantir sua eterna presença.

\section{Referências}

BELLO, J. Memórias de um senhor de engenho. 3. ed. Recife: Fundarpe, 1985.

FREYRE, G. Prefácio. In: BELLO, J. Memórias de um senhor de engenho. 3. ed. Recife: Fundarpe, 1985.

GALVÃO, A. de. O. Amansando meninos. João Pessoa: UFPB, 1998. 
HARVEY, D. A condição pós-moderna. São Paulo: Loyola, 1993.

JAMESON, F. Pós-modernismo: a lógica cultural do capitalismo tardio. São Paulo: Ática, 1996.

RÊGO, J. L. do. Meus verdes anos. Rio de Janeiro: J. Olympio, 1956.

RÊGO, J. L. do. Doidinho. 16. ed. Rio de Janeiro: J. Olympo, 1977. 